\title{
Autoantibodies directed against a1-adrenergic receptor and endothelin receptor $A$ in patients with prostate cancer
}

Gerd Wallukat ${ }^{1}$, Burkhard Jandrig ${ }^{2}$, Niels-Peter Becker ${ }^{1}$, Johann J. Wendler ${ }^{2}$, Peter Göttel ${ }^{1}$, Johannes Müller ${ }^{1}$, Martin Schostak ${ }^{2}$ and Ingolf Schimke ${ }^{1^{*}}$ (D)

\begin{abstract}
Background: For prostate cancer, signaling pathways induced by over-boarding stimulation of G-protein coupled receptors (GPCR) such as the endothelin, a1- and $\beta$-adrenergic, muscarinic and angiotensin 1 receptors were accused to support the carcinogenesis. However, excessive receptor stimulation by physiological receptor ligands is minimized by a control system that induces receptor sensitization and down-regulation. This system is missing when so-called "functional autoantibodies" bind to the GPCR (GPCR-AAB). If GPCR-AAB were found in patients with prostate cancer, uncontrolled GPCR stimulation could make these autoantibodies an additional supporter in prostate cancer.
\end{abstract}

Methods: Using the bioassay of spontaneously beating cultured rat neonatal cardiomyocytes, GPCR-AAB were identified, quantified and characterized in the serum of 25 patients (aged 56-78 years, median 70 years) with prostate cancer compared to 10 male patients (aged 48-82 years, median 64) with urinary stone disorders (controls).

Results: Of the cancer patients, 24 (96\%) and 17 (68\%), respectively, carried autoantibodies directed against the a1-adrenergic receptor (a1-AAB) and endothelin receptor $A$ (ETA-AAB). No patient was negative for both GPCR-AAB. In contrast, ETA-AAB and a1-AAB were absent in all (100\%) and 9 (90\%) of the 10 control patients, respectively. While a1-AAB targeted a specific epitope of the first extracellular loop of the a1-adrenergic receptor subtype $A$, an epitope of the second extracellular loop of the ETA receptor was identified as a target of ETA-AAB. As demonstrated in vitro, the functional activity of both autoantibodies found in prostate cancer can be neutralized by the aptamer BC007.

Conclusions: We hypothesized that $\mathrm{a} 1-\mathrm{AAB}$ and $\mathrm{ETA}-\mathrm{AAB}$, which are highly present in prostate cancer patients, could by their functional activity support carcinogenesis by excessive receptor stimulation. The in vitro demonstrated neutralization of a1- and ETA-AAB by the aptamer BC007 could open the door to complement the treatments already available for prostate cancer.

Keywords: Aptamer, Anti-a1-adrenergic receptor autoantibodies, Anti-endothelin receptor A autoantibodies, Functional autoantibodies, G-protein coupled receptor, Prostate cancer

${ }^{*}$ Correspondence: schimke@berlincures.de

${ }^{1}$ Berlin Cures GmbH, Knesebeckstraße 59-61, 10719 Berlin, Germany

Full list of author information is available at the end of the article

\section{Introduction}

For prostate cancer, one of the most common cancers in men [1] various pathogenic players are discussed, including signaling pathways mediated by G-protein coupled receptors (GPCR). Among the signaling pathways, those linked to endothelin [2-5], $\alpha 1$-adrenergic $[6,7]$, $\beta$-adrenergic $[7,8]$, muscarinic [9-11], and angiotensin 
1 receptors [12, 13], have been considered in relation to cell proliferation, metastasis and angiogenesis. As a key to explaining the potency of GPCR-mediated signaling in carcinogenesis, hyper-stimulation by its physiological receptor ligands is accused.

To prevent or minimize hyper-stimulation of the GPCR-mediated signaling by their physiological ligands, cells have developed a complex system of mechanisms including GPCR desensitization and down-regulation with a pivotal role of GPCR kinases and $\beta$-arrestin as summarized in [14]. Unfortunately, this GPCR self-controlling system does not work if so-called "functional autoantibodies" (GPCR-AAB) bind to the GPCR. This is well-documented for autoantibodies directed against the $\beta 1$-adrenergic receptor and the muscarinic 2 receptor, but has been more and more accepted as a general phenomenon of GPCR-AAB as summarized in [15].

Consequently, GPCR-AAB cause uncontrolled and over-boarding stimulation of the signaling pathways. This leads to the long-time perpetuation of downstream effects, making the GPCR-AAB a potent pathogenic driver or supporter [16, 17]. Among the diseases which are thought to be related to GPCR-AAB-associated effects, cardiovascular diseases [18] are predominant but not exclusive, as exemplarily demonstrated for patients with dementia [19].

Recently we published that patients with benign prostatic hyperplasia/low urinary tract syndrome (BPH/ LUTS) carry GPCR-AAB, especially those directed against the endothelin receptor $\mathrm{A}$ (ETA-AAB), and have discussed this finding in the context of vascular pathophysiology and cell growth [20]. In the present study we took a look at the GPCR-AAB situation in patients with prostate cancer where we found ETA-AAB as for patients with BPH/LUTS, but additionally GPCR-AAB directed against the $\alpha 1$-adrenergic receptor $(\alpha 1-\mathrm{AAB})$.

In addition, we characterized the GPCR-AAB in relation to the target region on their GPCR and showed in an in vitro experiment that the functional activity of GPCR$A A B$ can be neutralized, which opens a way to counteract GPCR-AAB in patients with prostate cancer.

\section{Materials and methods}

\section{Patients}

Of 25 patients (age 56-78 years, median 70 years) with prostate cancer (diagnosed based on [21]) (study group) and 10 male patients (age 48-82 years, median 64 years) with nephrolithiasis or urolithiasis (control group) treated at the Universitätsklinik für Urologie, Uroonkologie, robotergestützte und fokale Therapie, Otto von Guericke Universität Magdeburg, Germany, for prostate resection or lithotripsy/endoscopic removal, the serum collected for the certified bio-banking was analyzed. All patients signed informed consent forms approved by the Medical Ethics Committee of the Otto-von-Guericke University Magdeburg (\# 87/11). Clinic-pathological data of prostate cancer patients and controls can be seen in Table 1.

\section{Analytics Measurement of GPCR-AAB activity}

To identify and quantify the GPCR-AAB, localize its receptor binding site and demonstrate the ability to neutralize the functional activity of the GPCR-AAB activity, the bioassay of spontaneously beating cultured neonatal rat cardiomyocytes was used where the cells' chronotropic response to patients' IgG containing the GPCR$\mathrm{AAB}$ was recorded (for the mechanistic background of the assay, its structure, standardization and necessary sample preparation see [22, 23]). As defined: 1 beat $/ \mathrm{min}$ frequency increase $=1$ unit GPCR-AAB activity (positive chronotropy) and 1 beat $/ \mathrm{min}$ frequency decrease $=-1$ unit GPCR-AAB activity (negative chronotropy). The lower limits of detection (LLD) for positive and negative chronotropic GPCR-AAB were calculated as $4.0 \mathrm{U}$ and $-4.0 \mathrm{U}$, respectively. Based on $\mathrm{x} \pm 3 \mathrm{SD}$ of the GPCR$A A B$ level of more than 100 healthy volunteers, cut offs at $\geq 8.0 \mathrm{U}$ and $\leq-8.0 \mathrm{U}$ were defined for patient who are positive for positive chronotropic GPCR-AAB and negative chronotropic GPCR-AAB, respectively.

Through the intelligent use of GPCR blockers (exemplarily illustrated in Fig. 1 for three patients) the chronotropic response of the patients' IgG can be attributed to the respective GPCR-AAB. For the GPCR-AAB possibly relevant for prostate cancer as indicated in the introduction, the following blockers were used: $0.1 \mu \mathrm{mol} / \mathrm{l}$ BQ123 for ETA-AAB, $0.1 \mu \mathrm{mol} / \mathrm{l}$ atropine for $\mathrm{M} 2-\mathrm{AAB}$, $0.1 \mu \mathrm{mol} / \mathrm{l}$ losartan for AT1-AAB, $0.1 \mu \mathrm{mol} / \mathrm{l}$ propranolol for $\beta-A A B$, and $0.1 \mu \mathrm{mol} / 1$ prazosin for $\alpha 1-A A B$. Consequently, the GPCR-AAB activity was calculated based on the equation "mixed GPCR-AAB activity $=\mathrm{M} 2-\mathrm{AAB}$ activity + ETA-AAB activity $+\beta-A A B$ activity + AT1$\mathrm{AAB}$ activity $+\alpha 1-\mathrm{AAB}$ activity".

\section{Localizing of the receptor binding site}

To localize the extracellular binding site (extracellular loops) and map the specific epitope of the $\alpha 1$ adrenergic and ETA receptors targeted by $\alpha 1-\mathrm{AAB}$ and ETA-AAB, the bioassay was performed with IgG (GPCR-AAB) pre-incubated with an excess of peptides $(1 \mu \mathrm{g}$ peptide per $1 \mu \mathrm{g}$ IgG protein) synthesized by Biosyntan $\mathrm{GmbH}$, Berlin-Buch, Germany. As indicated in Table 2, blocking peptides were used representing the first, second and third extracellular loop of the ETA and $\alpha 1$-adrenergic receptor as well as peptides, which overlapped to represent the amino acid sequence of the first extracellular 
Table 1 Clinic-pathological data of prostate cancer patients and controls

\begin{tabular}{|c|c|c|}
\hline & $\mathrm{PCa}$ & Control \\
\hline Number individuals & 25 & 10 \\
\hline Mean/median age (years) & $68.9 / 69.9(56.3-78.2)$ & 65.0/64.1 (47.8-81.8) \\
\hline Mean/median height (cm) & 179/178 (168-196) & 177/179 (165-190) \\
\hline Mean/median weight (kg) & 87/84 (64-110) & $94 / 90(80-117)$ \\
\hline Mean/median BMI & $27.1 / 26.2(21.5-33.1)$ & $30.0 / 29.9(23.0-36.1)$ \\
\hline Mean/median PSA (ng/ml) & $238.1 / 21.5(6.2-3487)$ & \\
\hline \multicolumn{3}{|l|}{ Gleason score } \\
\hline $3+5$ & 2 & \\
\hline $4+4$ & 13 & \\
\hline $4+5$ & 5 & \\
\hline $5+4$ & 2 & \\
\hline $5+5$ & 3 & \\
\hline \multicolumn{3}{|l|}{ Gleason sum } \\
\hline 8 & 15 & \\
\hline 9 & 7 & \\
\hline 10 & 3 & \\
\hline \multicolumn{3}{|l|}{ Grade groups (ISUP) } \\
\hline 4 & 15 & \\
\hline 5 & 10 & \\
\hline \multicolumn{3}{|l|}{ Grading (c/p) } \\
\hline $\mathrm{T} 2 \mathrm{a}$ & 1 & \\
\hline $\mathrm{T} 2 \mathrm{~b}$ & 1 & \\
\hline $\mathrm{T} 2 \mathrm{C}$ & 5 & \\
\hline T3 & 4 & \\
\hline T3a & 4 & \\
\hline $\mathrm{T} 3 \mathrm{~b}$ & 10 & \\
\hline Lymph node metastasis pN0/pN1 & $9 / 6$ & \\
\hline Distant metastasis pM0/pM1 & $11 / 4$ & \\
\hline
\end{tabular}

loop of the $\alpha 1$-adrenergic and the second extracellular loop of the ETA receptor [23].

To demonstrate GPCR-AAB binding sites and the GPCR-AAB neutralization (see below), representative experiments were performed with a randomly selected sample size $>10 \%$ (samples of 4 and 5 patients, respectively) of the population size of 25 patients.

\section{$E T A-A A B$ and $a 1-A A B$ in vitro neutralization experiments}

The bioassay was also used to demonstrate the neutralization of $\alpha 1-\mathrm{AAB}$ and ETA-AAB activity by the aptamer BC007 [24].

\section{Results}

\section{Basics}

The study group of 25 patients with prostate cancer (age/years: median $=70, \min =56, \max =78$; Gleason score: median $=8, \min =8, \max =10$ ) and the control group of 10 patients with urinary stone disorders (aged 48-82 years, median 64 years) were not significantly different in age. All patients with prostate cancer presented with a Gleason score $\geq 8$.

\section{Analytics}

Figure 1, exemplarily for three patients, illustrates the measurement procedure of the GPCR-AAB activity in prostate cancer patients by means of the bioassay of spontaneously beating cultured neonatal rat cardiomyocytes. Based on bioassay handling, described in Materials and methods, one would assume, that patient 1 (black line) was negative for GPCR-AAB (activity<LLD), the second patient had positive chronotropic IgG and the third patient had negative chronotropic IgG. However, all three patients may represent a mixed activity, since the IgG of the patients could carry both positive and negative chronotropic GPCR-AAB, which may partially (patient 2 and 3 ) or completely (patient 1) cancel each other out. Therefore, an in-depth analysis with successive blocking experiments with receptor antagonists was necessary to find out which GPCR-AAB contributes to mixed activity. 


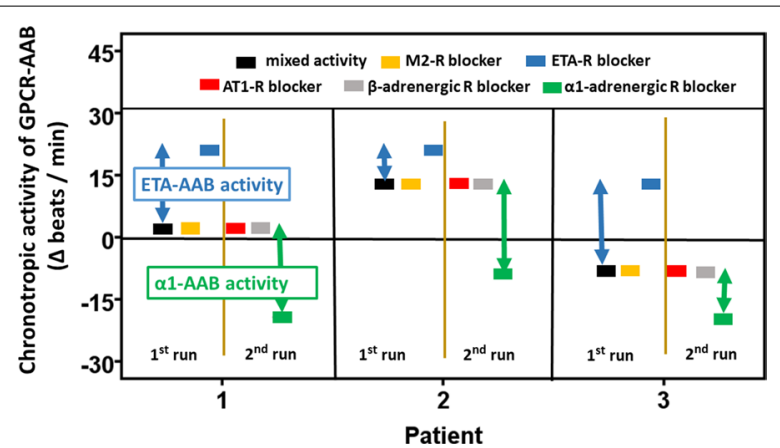

Fig. 1 Measurement strategy for autoantibodies directed against G-protein coupled receptors (GPCR-AAB) in the lgG of patients with prostate cancer using the bioassay of cultured spontaneously beating neonatal rat cardiomyocytes. The bioassay monitored the chronotropic activity of IgG resulting from the presence of positive and negative chronotropic GPCR-AABs. For GPCR-AAB differentiation and activity calculation, the bioassay was performed in two runs. The first run was performed in the absence of GPCR blockers and thereafter with successive addition of $0.1 \mu \mathrm{mol} / \mathrm{l}$ atropine and $0.1 \mu \mathrm{mol} / \mathrm{I} \mathrm{BQ} 123$ to block the muscarinic receptor 2 and endothelin receptor $A$. The second run was performed in the absence of GPCR blockers and thereafter with successive addition of $0.1 \mu \mathrm{mol} / \mathrm{l}$ losartan, $0.1 \mu \mathrm{mol} / /$ propranolol and $0.1 \mu \mathrm{mol} / \mathrm{l}$ prazosin to block the AT1, $\beta$-adrenergic, and a 1 -adrenergic receptors. Calculation of the GPCR-AAB activity: mixed GPCR-AAB activity $=M 2-A A B$ activity + ETA-AAB activity + $\beta-A A B$ activity + AT1-AAB activity $+a 1-A A B$ activity. Blue arrows indicate the ETA-AAB activity. Green arrows indicate the a1-AAB activity

As shown in Fig. 1, a first bioassay run was performed to look for negative chronotropic GPCR-AAB, such as autoantibodies directed against the muscarinic receptor 2 (M2-AAB) and ETA-AAB. Blockade of the muscarinic receptor 2 (yellow line) with atropine did not affect the beat rate of the cells as compared with the unblocked rate (mixed activity), which excluded the presence of M2-AAB. After successive blockade of the endothelin A receptor with BQ123 (blue line), in contrast, the cells responded to the IgG of patient 1 and patient 2 with increased beat rate. For patient 3 , the beat rate switched from decreased to increased rate, respectively. This indicated the presence of ETA-AAB in the IgG of all three patients. To assign the positive chronotropic activity to a specific GPCR-AAB and to calculate this activity, the bioassay was performed in a second run with successive addition of blockers for AT1 (red line), $\beta$-adrenergic (grey line), and $\alpha 1$-adrenergic receptors (green line). AT1 and $\beta$-adrenergic receptor blockers losartan and propranolol, respectively, had no effect on the mixed activity of the patients' IgG, indicating the absence of AT1-AAB, $\beta 1-A A B$, and $\beta 2-A A B$ in the patients' IgG. In contrast, blocking the $\alpha 1$-adrenergic receptor with prazosin reduced the beat rate of cells as an indicator of $\alpha 1-\mathrm{AAB}$ in the patients' IgG.

\section{Autoantibody pattern}

Of the 25 cancer patients (Fig. 2), 24 (96\%) presented with a $\alpha 1-\mathrm{AAB}$ level above the cut off $\geq 8.0 \mathrm{U}$, indicating $\alpha 1-\mathrm{AAB}$ positivity in these patients. With respect to the ETA-AAB, $14(56 \%)$ patients were clearly positive $(<-8 \mathrm{U})$ and $3(12 \%)$ patients exactly met the cut off with their ETA-AAB levels. Consequently, by the definition related to the cut off, 17 (68\%) patients were positive for ETA-AAB, whereas 8 (32\%) were negative for ETA-AAB. Because none of the patients that were negative for both GPCR-AAB, all 25 patients with prostate cancer were GPCR_AAB positive.

In contrast, ETA-AAB were undetectable in all $(100 \%)$ and $\alpha 1-\mathrm{AAB}$ in $9(90 \%)$ of the 10 controls. Interestingly,

Table 2 Peptides used to localize (loop analysis, epitope mapping) the binding site of the endothelin receptor $A$ and the a1-adrenergic receptor targeted by ETA-AAB and a1-AAB

\begin{tabular}{lll}
\hline A & Endothelin receptor $\mathbf{A}$ & a1-adrenergic receptor \\
\hline Loop 1 & ${ }^{134}$ LPINVFKLLAGRWPFDHNDFGVFLCKL ${ }^{160}$ & ${ }^{89}$ LGYWAFGRVFCN $^{100}$ \\
Loop 2 & ${ }^{229}$ FEYRGEQHKTCMLNATSKFMEFYQDVKD ${ }^{256}$ & ${ }^{168}$ PAPEDETICQINEE ${ }^{181}$ \\
Loop 3 & ${ }^{329}{ }^{29}$ KKTVYNEMDKNRCELLSFLL ${ }^{348}$ & a1-adrenergic receptor first loop \\
B & Endothelin receptor A second loop & LGYWAFGRVFCN \\
Loop & FEYRGEQHKTCMLNATSKFMEFYQDVKD & FWAFGR \\
P1 & FEYRGEQ & GRVFCDV \\
P2 & EQHKTCM & \\
P3 & MLNATSK & \\
P4 & SKFMEFY & \\
P5 & FYQDVKD &
\end{tabular}

A: Peptides representing the first, second and third extracellular loops of the endothelin receptor A and the a1-adrenergic receptor. B: Peptides with overlapping loop sequence representing the second extracellular loop (endothelin receptor $A$ ) and the first extracellular loop (a1-adrenergic receptor)

ETA and a1-adrenergic receptor (ETA receptor: ${ }^{134}$ LPINVFKLLAGRWPFDHNDFGVFLCKL ${ }^{160},{ }^{229} \mathrm{FEYRGEQHKTCMLNATSKFMEFYQDVKD}{ }^{256}$, and

${ }^{329}$ KKTVYNEMDKNRCELLLSFLL ${ }^{348}$ ); (a1-adrenergic receptor: ${ }^{89}$ LGYWAFGRVFCN $^{100},{ }^{168}$ PAPEDETICQINEE $^{181}$, and ${ }^{298}$ FPDFKPSETVFKIVIFWLGYLNSC $^{329}$ ) 


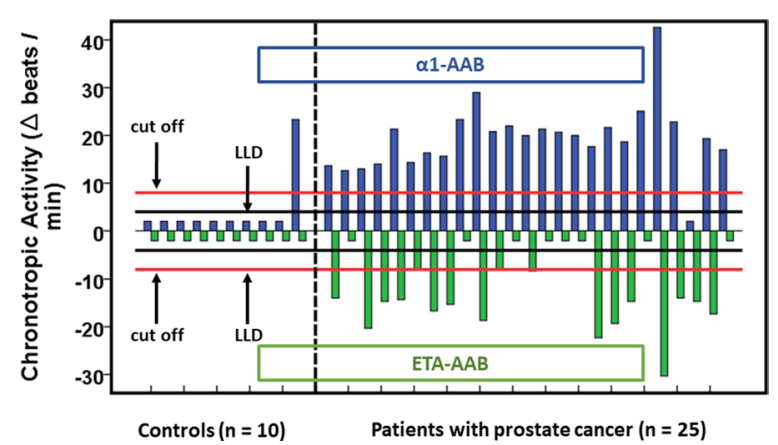

Fig. 2 Chronotropic activity ( $\triangle$ beats/min) of autoantibodies directed against the a1-adrenergic receptor (a1-AAB) and endothelin receptor $A$ (ETA-AAB) in patients with prostate cancer as compared with control patients suffering from urinary stone disorders. For measurement, the bioassay of spontaneously beating cultured neonatal rat cardiomyocytes was performed in the presence of the patients' IgG without and with the presence of specific receptor blockers (endothelin receptor A: $0.1 \mu \mathrm{mol} / \mathrm{l}$ BQ 123, muscarinic 2 receptor: $0.1 \mu \mathrm{mol} / /$ atropine, $\beta$-adrenergic receptor: $0.1 \mu \mathrm{mol} / /$ propranolol, AT-1 receptor: $0.1 \mu \mathrm{mol} / \mathrm{l}$ losartan, a1-adrenergic receptor: $0.1 \mu \mathrm{mol} / /$ prazosin). Values below the lower limit of detection (LLD) were displayed as half range values. $L L D=\triangle 4$ beats/ min for a 1-AAB, $\triangle-4$ beats/min for ETA-AAB; cut off (separating healthy from disease subjects $)=\triangle 8$ beats per $/ \mathrm{min}$ for a $1-A A B, \triangle$ -8 beats/min for ETA-AAB

the one control with a strong increase in the $\alpha 1-\mathrm{AAB}$ level was the only one that presented with a defined additional diagnosis of psoriasis.

\section{Autoantibody characteristics}

As demonstrated in Fig. 3a for $4(\alpha 1-\mathrm{AAB})$ and 5 (ETA-AAB), respectively, randomly selected patients, $\alpha 1-\mathrm{AAB}$ targeted the first extracellular receptor loop of $\alpha 1$-adrenergic receptor, and related to the blocking peptide, the subtype A; there specifically an epitope located tightly to the $\mathrm{N}$-terminus of the receptor loop (Fig. 3b). For ETA-AAB, the second extracellular loop of their receptor was identified as the target (Fig. 3a) with an epitope located in the middle region of the loop. As shown in Fig. 3c for four patients that were positive for ETA-AAB and $\alpha 1-A A B$, pre-treatment of their IgG with the aptamer $\mathrm{BC} 007$ resulted in the loss of either $\alpha 1-\mathrm{AAB}$ and ETA-AAB.

\section{Discussion}

The discovery of functionally active autoantibodies (GPCR-AAB) in the blood of patients that bind to GPCR for uncontrolled stimulation, which explains the perpetuation of pathogenically important downstream effects inside cells, has introduced a new class of autoimmune diseases denoted as functional autoantibody diseases. The bioassay of spontaneously beating cultured neonatal rat cardiomyocytes [23], is the most commonly used analytical tool for the identification and characterization of GPCR-AAB found in human serum.

Having recently shown with this bioassay that patients with BPH/LUTS carry functional autoantibodies, such as ETA-AAB, we used in the present study this tool to demonstrate that patients with prostate cancer also carry GPCR-AAB, but positive chronotropic $\alpha 1-\mathrm{AAB}$ in addition to the negative chronotropic ETA-AAB.

ETA-AAB were found in the majority $(68 \%)$ of patients with prostate cancer, targeting the second extracellular receptor loop, an epitope located in the middle region of the loop. This is insignificantly different from our findings with a $60 \%$ ETA-AAB positivity in patients with $\mathrm{BPH} / \mathrm{LUTS}$ in whom the ETA-AAB target was comparably localized [20].

In contrast to patients with BPH/LUTS, where ETA$\mathrm{AAB}$ were the only GPCR-AAB, nearly all patients with prostate cancer additionally carried $\alpha 1-\mathrm{AAB}$ which targeted the first extracellular loop, and specifically an epitope localized near the loop's N-terminus. $\alpha 1$-AABs were also frequently found in patients with idiopathic pulmonary hypertension, diabetes mellitus, drug-induced cancer [16, 17], psoriasis [25] and dementia [19], where the $\alpha 1-\mathrm{AAB}$ targeted the second extracellular receptor loop. However, $\alpha 1-\mathrm{AAB}$ targeting the first extracellular loop were found in dementia patients [26].

GPCR-AAB were not found in our control group, except one control who carried $\alpha 1-\mathrm{AAB}$. Interestingly, this man suffered from psoriasis in which $\alpha 1-\mathrm{AAB}$ positivity was described [27].

Regarding the mechanisms to be considered for ETA$\mathrm{AAB}$ - and $\alpha 1$-AAB-induced pathologies, many of these with the potency of generalization were discussed for ETA-AAB focused on systemic sclerosis [27] and for $\alpha 1-\mathrm{AAB}$ focused on Alzheimer's disease [26].

For ETA-AAB in prostate cancer must be considered that their target, the ETA receptor, was identified in the prostate in the 1990s [28, 29], where its expression increased with tumor stage, grade and recurrence [30]. Overstimulation of the endothelin receptor A led to pathogenic effects involved in tumor growth, epithelial mesenchymal transition, apoptosis, metastasis, angiogenesis, and drug resistance, thus probably contributing to prostate carcinogenesis [2-5].

Unfortunately, a meta-analysis of clinical trials of ETA receptor antagonists for the treatment of hormone refractory prostate cancer did not show a significant benefit for overall or progression-free survival. However, patients benefited from a reduction in cancer-related bone pain and skeletal events [31].

To approximate the carcinogenic effects of $\alpha 1-\mathrm{AAB}$, several arguments for the effects of $\alpha 1$-adrenergic 
Fig. 3 a Autoantibodies directed against the a1-adrenergic receptor (a1-AAB) and endothelin receptor A (ETA-AAB) of patients with prostate cancer target the first and second extracellular receptor loops, respectively, of their related receptors. Using the bioassay of spontaneously beating cultured neonatal rat cardiomyocytes, the chronotropic activity of the patients' IgG (a1-AAB: $n=4$; ETA-AAB: $n=5$ ) was measured in the presence or absence of the competition of peptides representing the amino acid sequence of the extracellular receptor loops. Values below the lower limit of detection (LLD; a $1-A A B=\triangle 4$ beats $/ \mathrm{min}$, ETA-AAB $=\Delta-4$ beats $/ \mathrm{min}$ ) were displayed as half range values. $\mathbf{b}$ Mapping of the first extracellular loop of the $\mathrm{a} 1$-adrenergic receptor and the second extracellular loop of the endothelin receptor $A$ targeted by the related autoantibodies (a1-AAB, anti-a1-adrenergic receptor autoantibodies; ETA-AAB, anti-endothelin receptor $A$ autoantibodies) of patients with prostate cancer. Using the bioassay of spontaneously beating cultured neonatal rat cardiomyocytes, the ETA-AAB activity and a1-AAB activity (mean $\pm S D$ ) of the patients' IgG (a1-AAB: $n=4$; ETA-AAB: $n=5$ ) was measured in the presence or absence of competing peptides that overlapped to represent the first extracellular loop of the a1-adrenergic receptor (P1: FWAFGR, P2: GRVFCDV) and the second extracellular loop of the endothelin receptor A (P1: FEYRGEQ, P2: EQHKTCM, P3: MLNATSK, P4: SKFMEFY, P5: FYQDVKD). Values below the lower limit of detection (LLD; $\mathrm{a} 1-\mathrm{AAB}=\triangle 4$ beats $/ \mathrm{min}$, $E T A-A A B=\triangle-4$ beats $/ \mathrm{min}$ ) were displayed as half range values. $\mathbf{C}$ In vitro neutralization by aptamer BC007 of autoantibodies directed against the a1-adrenergic receptor (a1-AAB) endothelin receptor A (ETA-AAB) of patients with prostate cancer. Using the bioassay of spontaneously beating cultured neonatal rat cardiomyocytes, the $E T A-A A B$ and a1-AAB chronotropic activity of the patients' $\lg (n=5)$ was measured in the presence or absence of the $0.1 \mu \mathrm{mol} / \mathrm{L}$ aptamer BC007 (sequence: GGTTGGTGTGGTTGG) or scrambled control (sequence: GGTGGTGGTTGTGGT). Values below the lower limit of detection (LLD; $a 1-A A B=\triangle 4$ beats $/ \mathrm{min}, E T A-A A B=\Delta-4$ beats $/ \mathrm{min}$; cut off separating healthy subjects from patients: $a 1-A A B=\triangle 8$ beats/ min, $E T A-A A B=\Delta-8$ beats $/ \mathrm{min}$ ) were displayed as half range values
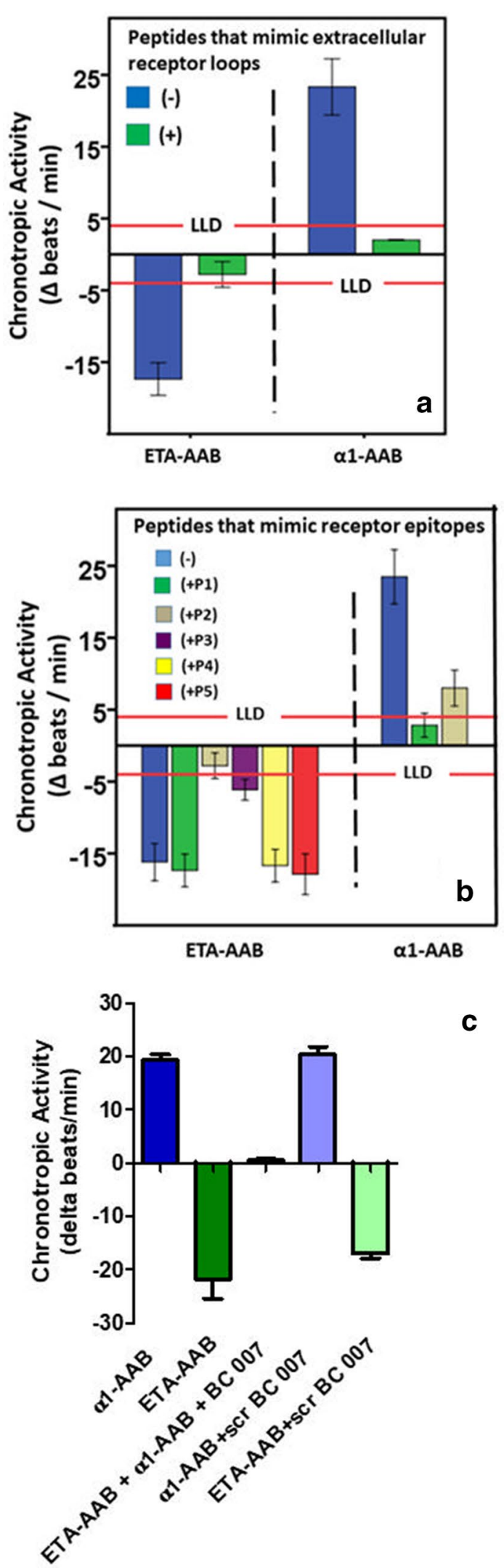
receptor-mediated signaling on the development, progression and prevention of prostate cancer were summarized in [7].

The $\alpha 1$-adrenergic receptor subtype $\mathrm{A}$ is localized in the prostate [32,33] and mRNA and receptor increase were found in the aging gland [34, 35]. Proliferation in prostate cancer epithelium was demonstrated after $\alpha 1$-adrenergic receptor stimulation [36]. Due to potentially carcinogenic effects seen after stimulation of the $\alpha 1$-adrenergic receptor in prostate cell lines, suitable blockers have been proposed for the treatment of prostate cancer [37]. Retrospective cohort and observational studies did indeed show a reduced incidence of prostate cancer if patients treated with $\alpha 1$ - adrenergic receptor blockers for hypertension and/or benign prostate hyperplasia; in the latter patients the blockers increased the apoptotic index and reduced the vascularity of the prostate tumor [36].

For some antitumor effects of the $\alpha 1$-adrenergic receptor antagonists, however, in addition to the patient benefit discussed as a result of the $\alpha 1$-adrenergic receptor antagonization, a DNA breaking activity of the blockers, which leads to mitotic arrest of the cell cycle and mitochondrial damage, must be considered [37].

By combining ETA-AAB and $\alpha 1-\mathrm{AAB}$ in prostate cancer with the downstream effects after agonist binding and the lack of prevention of GPCR over-stimulation after GPCR-AAB binding [15], we postulate the establishment of GPCR-AAB/GRCR axes that should be more potent than the physiological axes in over-stimulation and induction of pathologies.

As illustrated in Fig. 4 (using data published in [3840]), the different binding sites were considered the reason for the discrepancy between physiological agonists and GPCR-AAB in GPCR stimulation and control. While physiological agonists bind in a hydrophobic pocket of GPCR, GPCR-AAB binds to the extracellular loops and, due to the bivalent nature of IgG, crosslink the GPCR to realize the functional activity of GPCR-AAB without control.

It remains speculative, however, whether the postulated creation of the $\alpha 1-\mathrm{AAB} / \alpha 1$-adrenergic and ETA-AAB/ ETA receptor axes in prostate cancer patients overpowers the drug-induced receptor antagonization that was intended to benefit patients.

However, it should not be concealed that, derived mainly from studies of cardiovascular diseases associated with GPCR-AAB, there were convincing data that demonstrated a more pronounced patient benefit if antagonist treatment was combined with an attack on the GPCR-AAB [41].

In case future studies manifest the pathogenic roles of $\alpha 1-\mathrm{AAB}$ and ETA-AAB in prostate cancer, a treatment

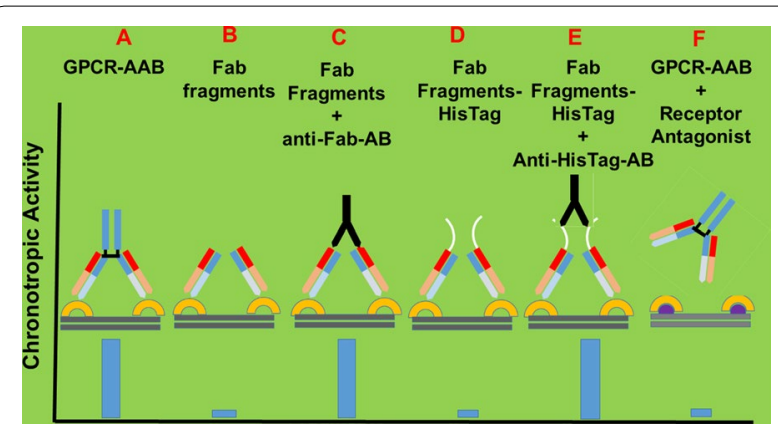

Fig. 4 Cross-linking of G-protein coupled receptors (GPCR) by the corresponding functional autoantibodies (GPCR-AAB); the key event for receptor mediated signaling after receptor binding of GPCR-AAB is illustrated [21] Using the bioassay of spontaneously beating cultured neonatal rat cardiomyocytes, the chronotropic activity of GPCR-AAB in the absence (a) and presence of a related receptor blocker ( $\mathbf{f}$ ) as well as of monomeric Fab fragments (b), monomeric Fab fragments cross-linked by anti-Fab-antibodies (c), monomeric Fab fragments coupled to polyhistidine tag (d) and Fab fragments coupled to polyhistidine tag cross-linked by polyhistidine antibodies

strategy targeting the GPCR-AAB should be considered. As a first step of such treatment strategy, we demonstrated the in vitro neutralization of the prostate cancer associated GPCR-AAB with the drug BC 007.

The recently successfully completed phase 1 clinical trial with $\mathrm{BC} 007$ in combination with the successful demonstration of GPCR-AAB neutralization in humans $[42,43]$ could open the door for studies to evaluate in vivo GPCR-AAB neutralization with $\mathrm{BC} 007$ as a new complementary therapeutic strategy for patients with prostate cancer.

\section{Conclusion}

Of patients with prostate cancer, nearly $96 \%$ of them carried positive chronotropic autoantibodies directed against the first extracellular loop of the $\alpha 1$-adrenergic receptor ( $\alpha 1-\mathrm{AAB})$ and $68 \%$ negative chronotropic autoantibodies directed against the second extracellular loop of the endothelin receptor A (ETA-AAB). We postulate $\alpha 1-\mathrm{AAB} / \alpha 1$-adrenergic receptor and ETA-AAB/ endothelin receptor $A$ axes for these patients, that, in contrast to the related axes based on the physiological receptor ligands, lack control mechanisms, such as receptor desensitization and downregulation to counteract over-boarding stimulation.

Therefore, the stimulation of both GPCR-AAB axes in patients with prostate cancer should long-lasting activate downstream pathways whose carcinogenic potency is probably more potent as compared to the axes considering physiological ligands.

Last but not least, we believe that treatment strategies that counteract $\alpha 1-\mathrm{AAB}$ and ETA-AAB could 
complement the standard treatment for patients with prostate cancer. In this context, the in vivo neutralization of $\alpha 1-\mathrm{AAB}$ and ETA-AAB by treatment with the aptamer $\mathrm{BC} 007$ could be an option for the future.

\begin{abstract}
Authors' contributions
GW study design, autoantibody analytics; BJ bio-bank responsible, material sampling and preparation, N-PB manuscript preparation, study organization, statistical data evaluation; JW patient acquisition, clinical evaluation, PG study organization, responsible for the labor quality management system; JM study organization, responsible for labor quality management system MS patient acquisition, clinical evaluation, responsible for the ethics application; IS study design, statistical data evaluation, manuscript preparation. All authors read and approved the final manuscript.
\end{abstract}

\section{Funding}

No funding.

\section{Availability of data and materials}

All data generated or analyzed during this study are included in this published article.

\section{Ethics approval and consent to participate}

The study has been performed in accordance with the Declaration of Helsinki. Certified bio-bank stored human sampled were analyzed. All patients signed informed consent forms approved by the Medical Ethics Committee of the Otto-von-Guericke University Magdeburg (\# 87/11).

\section{Consent for publication}

Not applicable.

\section{Competing interests}

The authors declare that the study was not funded by any public, commercial or private funds. Gerd Wallukat, Niels-Peter Becker, Peter Göttel, Johannes Müller and Ingolf Schimke as employees and shareholder (GW, PG, JM, IS) of Berlin Cures $\mathrm{GmbH}$ declare that Berlin Cures $\mathrm{GmbH}$ only provided support in the form of salaries and research materials but did not have any additional role in the study design, data collection, analysis and statistical evaluation, decision to publish or preparation of the manuscript. Burkhard Jandrig, Johann J. Wendler and Martin Schostak declare that they have no conflict of interest.

\section{Author details}

${ }^{1}$ Berlin Cures GmbH, Knesebeckstraße 59-61, 10719 Berlin, Germany. ${ }^{2}$ Universitätsklinik für Urologie, Uroonkologie, robotergestützte und fokale Therapie, Otto von Guericke Universität, Magdeburg, Germany.

Received: 8 March 2020 Accepted: 20 July 2020

Published online: 25 September 2020

\section{References}

1. Bray F, Ren JS, Masuyer E, Ferlay J. Global estimates of cancer prevalence for 27 sites in the adult population in 2008. Int J Cancer. 2013;132(5):1133-45.

2. Bagnato A, Rosano L. The endothelin axis in cancer. Int J Biochem Cell Biol. 2008;40(8):1443-51.

3. Irani S, Salajegheh A, Smith RA, Lam AK. A review of the profile of endothelin axis in cancer and its management. Crit Rev Oncol Hematol. 2014;89(2):314-21.

4. Wang R, Dashwood RH. Endothelins and their receptors in cancer: identification of therapeutic targets. Pharmacol Res. 2011;63(6):519-24.

5. Barton M, Yanagisawa M. Endothelin: 30 years from discovery to therapy. Hypertension. 2019;74(6):1232-65.

6. Kyprianou N, Chon J, Benning CM. Effects of alpha(1)-adrenoceptor (alpha(1)-AR) antagonists on cell proliferation and apoptosis in the prostate: therapeutic implications in prostatic disease. Prostate Suppl. 2000;9:42-6.

7. Wade CA, Goodwin J, Preston D, Kyprianou N. Impact of alpha-adrenoceptor antagonists on prostate cancer development, progression and prevention. Am J Clin Exp Urol. 2019;7(1):46-60.

8. Tang J, Li Z, Lu L, Cho CH. Beta-Adrenergic system, a backstage manipulator regulating tumour progression and drug target in cancer therapy. Semin Cancer Biol. 2013;23(6 Pt B):533-42.

9. Guo L, Liu Y, Ding Z, Sun W, Yuan M. Signal transduction by M3 muscarinic acetylcholine receptor in prostate cancer. Oncol Lett. 2016;11(1):385-92.

10. Spindel ER. Muscarinic receptor agonists and antagonists: effects on cancer. Handb Exp Pharmacol. 2012;208:451-68.

11. Witte $L P$, Chapple CR, de la Rosette JJ, Michel MC. Cholinergic innervation and muscarinic receptors in the human prostate. Eur Urol. 2008;54(2):326-34.

12. Uemura $\mathrm{H}$, Ishiguro $\mathrm{H}$, Kubota Y. Pharmacology and new perspectives of angiotensin II receptor blocker in prostate cancer treatment. Int J Urol. 2008;15(1):19-26.

13. Uemura H, Nakaigawa $N$, Ishiguro H, Kubota Y. Antiproliferative efficacy of angiotensin II receptor blockers in prostate cancer. Curr Cancer Drug Targets. 2005;5(5):307-23.

14. Rajagopal S, Shenoy SK. GPCR desensitization: acute and prolonged phases. Cell Signal. 2018;41:9-16.

15. Becker NP, Goettel P, Mueller J, Wallukat G, Schimke I. Functional autoantibody diseases: basics and treatment related to cardiomyopathies. Front In Biosci. 2019;24:14.

16. Bornholz B, Wallukat G, Roggenbuck D, Schimke I. Chapter 3-Autoantibodies Directed Against G-Protein-Coupled Receptors in Cardiovascular Diseases: Basics and Diagnostics. In: Nussinovitch U, editor. The Heart in Rheumatic, Autoimmune and Inflammatory Diseases. Cambridge: Academic Press: 2017. p. 49-63.

17. Wallukat G, Schimke I. Agonistic autoantibodies directed against G-protein-coupled receptors and their relationship to cardiovascular diseases. Semin Immunopathol. 2014;36(3):351-63.

18. Becker NP, Muller J, Gottel P, Wallukat G, Schimke I. Cardiomyopathy-an approach to the autoimmune background. Autoimmun Rev. 2017;16(3):269-86.

19. Wallukat G, Pruss H, Muller J, Schimke I. Functional autoantibodies in patients with different forms of dementia. PLOS ONE. 2018;13(3):e0192778.

20. Wallukat G, Jandrig B, Kunze R, Wendler JJ, Muller J, Schostak M, et al. Autoantibodies directed against the endothelin a receptor in patients with benign prostatic hyperplasia. Prostate. 2017;77(5):458-65.

21. Leitlinienprogramm. Onkologie (Deutsche Krebsgesellschaft, Deutsche Krebshilfe, AWMF): Interdisziplinäre Leitlinie der Qualität S3 zur Früherkennung, Diagnose und Therapie der verschiedenen Stadien des Prostatakarzinoms, Langversion 5.0, 2018, AWMF Registernummer: 043/022OL, http://www.leitlinienprogramm-onkolo-gie.de/leitlinien/prostatakarzino m/ (Accessed 06 Nov 2019).

22. Lorenzen-Schmidt I, Schmid-Schonbein GW, Giles WR, McCulloch AD, Chien S, Omens JH. Chronotropic response of cultured neonatal rat ventricular myocytes to short-term fluid shear. Cell Biochem Biophys. 2006:46(2):113-22.

23. Wallukat G, Wenzel K, Schimke I. Analytics of functional autoantibodies in patients with chagas disease. Methods Mol Biol. 2019;1955:247-61.

24. Schimke I, Haberland A, Wallukat G. Use of Aptamers in Therapy and/or Diagnosis of Autoimmune Diseases. Charite-Universitaetsmedizin Berlin; Max-Delbrueck-Centrum Fuer Molekulare Medizin; Schimke, Ingolf; Haberland, Annekathrin; Wallukat, Gerd, 2012.

25. Wallukat G, Schimke I. Lethal immunoglobulins: Autoantibodies and sudden cardiac death, Autoimmun Rev. 2019 Feb 14. pii: S15689972(19)30037-0. https://doi.org/10.1016/j.autrev.2018.12.005. [Epub ahead of print] of Ryabkova VA et al. Autoimmun Rev 2019; 18(7): 749-750.

26. Karczewski P, Hempel P, Bimmler M. Role of alpha1-adrenergic receptor antibodies in Alzheimer's disease. Front Biosci. 2018;23:2082-9.

27. Cabral-Marques O, Riemekasten G. Vascular hypothesis revisited: role of stimulating antibodies against angiotensin and endothelin receptors in the pathogenesis of systemic sclerosis. Autoimmun Rev. 2016;15(7):690-4. 
28. Kobayashi S, Tang R, Wang B, Opgenorth T, Stein E, Shapiro E, et al. Localization of endothelin receptors in the human prostate. J Urol. 1994;151(3):763-6.

29. Le Brun G, Moldovan F, Aubin P, Ropiquet F, Cussenot O, Fiet J. Identification of endothelin receptors in normal and hyperplasic human prostate tissues. Prostate. 1996;28(6):379-84.

30. Godara G, Pecher S, Jukic DM, D'Antonio JM, Akhavan A, Nelson JB, et al. Distinct patterns of endothelin axis expression in primary prostate cancer. Urology. 2007;70(1):209-15.

31. Qiao L, Liang Y, Li N, Hu X, Luo D, Gu J, et al. Endothelin-A receptor antagonists in prostate cancer treatment-a meta-analysis. Int J Clin Exp Med. 2015;8(3):3465-73.

32. Civantos Calzada B. Aleixandre de Artinano A. Alpha-adrenoceptor subtypes. Pharmacol Res. 2001;44(3):195-208.

33. Kobayashi S, Tang R, Shapiro E, Lepor H. Characterization and localization of prostatic alpha 1 adrenoceptors using radioligand receptor binding on slide-mounted tissue section. J Urol. 1993;150(6):2002-6.

34. Kojima Y, Sasaki S, Shinoura H, Hayashi Y, Tsujimoto G, Kohri K. Quantification of alpha1-adrenoceptor subtypes by real-time RT-PCR and correlation with age and prostate volume in benign prostatic hyperplasia patients. Prostate. 2006;66(7):761-7.

35. Moriyama N, Yamaguchi T, Takeuchi T, Sakamoto E, Ueki T, Tsujimoto G, et al. Semiquantitative evaluation of alpha1 A-adrenoceptor subtype mRNA in human hypertrophied and non-hypertrophied prostates: regional comparison. Life Sci. 1999;64(3):201-10.

36. Thebault S, Flourakis M, Vanoverberghe K, Vandermoere F, Roudbaraki M, Lehen'kyi $\mathrm{V}$, et al. Differential role of transient receptor potential channels in Ca2 + entry and proliferation of prostate cancer epithelial cells. Cancer Res. 2006:66(4):2038-47.
37. Batty M, Pugh R, Rathinam I, Simmonds J, Walker E, Forbes A, et al. The role of alpha1-adrenoceptor antagonists in the treatment of prostate and other cancers. Int J Mol Sci. 2016:17(8):1339.

38. Elias F. Detection of Trypanosoma cruzi DNA and analysis of the B cell in the heart tissue of patients with chronic Chagas' heart disease. Dissertation. Dissertation, FU Berlin 2011.

39. Elies R, Fu LX, Eftekhari P, Wallukat G, Schulze W, Granier C, et al. Immunochemical and functional characterization of an agonist-like monoclonal antibody against the $\mathrm{M} 2$ acetylcholine receptor. Eur J Biochem. 1998;251(3):659-66.

40. Hoebeke J. Molecular mechanisms of anti-G-protein-coupled receptor autoantibodies. Autoimmunity. 2001;34(3):161-4.

41. Dandel M, Wallukat G, Englert A, Lehmkuhl HB, Knosalla C, Hetzer R. Longterm benefits of immunoadsorption in beta(1)-adrenoceptor autoantibody-positive transplant candidates with dilated cardiomyopathy. Eur J Heart Fail. 2012;14(12):1374-88.

42. Mueller J, Haberland A, Becker N-P, Wenzel K, Wallukat G, Goettel P, et al. THE DNA-based therapeutic agent BC 007 completely neutralizes agonistic autoantibodies directed against $\beta 1$-adrenoceptors: results of a phase 1 trial. J Am Coll Cardiol. 2018;71(11 Supplement):A645.

43. Müller J, Haberland A, Wallukat G, Becker N-P, Wenzel K, Göttel P, et al. The DNA-based drug BC 007 neutralizes agonistically acting autoantibodies directed against $\mathrm{G}$ protein-coupled receptors-successful mode of action demonstrated in clinical phase 1 trial. Chim Oggi. 2019;2(Mar/Apr):65-7.

\section{Publisher's Note}

Springer Nature remains neutral with regard to jurisdictional claims in published maps and institutional affiliations.
Ready to submit your research? Choose BMC and benefit from:

- fast, convenient online submission

- thorough peer review by experienced researchers in your field

- rapid publication on acceptance

- support for research data, including large and complex data types

- gold Open Access which fosters wider collaboration and increased citations

- maximum visibility for your research: over $100 \mathrm{M}$ website views per year

At BMC, research is always in progress.

Learn more biomedcentral.com/submissions 